\title{
Evaluation of the bi-phase composites failure model for finite element impact analyses of loaded plates
}

\author{
K. M. Mikkor* $\quad$ R. S. Thomson ${ }^{\dagger} \quad$ I. Herszberg ${ }^{\dagger}$ \\ A. P. Mouritz*
}

(Received 11 November 2005; revised 19 May 2006)

\begin{abstract}
We assess the use of the Pam-Crash bi-phase failure model for the explicit finite element impact analysis of preloaded composite plates. The results obtained were compared with experimental work to corroborate the accuracy of the model. Overall, the trends displayed in the finite element simulations were consistent with experimental data, although quantitatively finite element results were conservative. The development of the model raised a number of issues concerning the accuracy and limitations of modelling techniques available.
\end{abstract}

*School of Aerospace Mechanical \& Manufacturing Engineering, RMIT University, Melbourne, Australia.

${ }^{\dagger}$ Cooperative Research Centre for Advanced Composite Structures Ltd, Melbourne, Australia. mailto:i.herszberg@crc-acs.com.au

See http://anziamj.austms.org.au/V47EMAC2005/Mikkor for this article, (C) Austral. Mathematical Soc. 2006. Published June 23, 2006. ISSN 1446-8735 


\section{Contents}

1 Introduction

C70

2 Finite element modelling methodology

C71

2.1 Bi-phase model . . . . . . . . . . . . . . . C C72

3 Results - tension and compression tests

C73

4 Results - impact without preload models

C73

5 Results - impact under preload models $\quad$ C78

5.1 Damage analysis . . . . . . . . . . . . . C C78

5.2 Mesh size sensitivity . . . . . . . . . . . . . . . C79

5.3 Panel size . . . . . . . . . . . . . . . . . . . . C C79

5.4 Residual tensile strength . . . . . . . . . . . . . . C81

6 Discussion of modelling limitations

C82

7 Conclusion

C83

References

C84

\section{Introduction}

Despite having superior mechanical properties such as high stiffness and strength, good corrosion resistance and light weight, composites are particularly susceptible to impact damage during maintenance, manufacture and in-flight [1]. This type of damage is often internal and undetectable, but can significantly reduce mechanical properties $[1,2,7]$ or even cause catastrophic failure if the structure is under load during impact $[4,8]$.

A significant amount of work has been conducted into the impact be- 
haviour of composites, yet little of this has focused on preloaded composites $[5,6]$. However, many in-flight impact events occur when the structure is under some form of load, such as a highly loaded flap being impacted by runway debris upon takeoff. As such, the study of impact behaviour and damage tolerance on preloaded composites represents a critical area of research.

This paper outlines the development of a $\mathrm{FE}$ model using the explicit FE code Pam-Crash. The purpose of the model was to accurately simulate and predict the impact behaviour of carbon fibre reinforced plastic materials when subject to preloads. An attempt was made to simulate experimental data presented in [4], which was also used in the validation process. The effect of various modelling parameters on the impact behaviour displayed by the model was investigated. Furthermore, the model was utilised to conduct parametric studies into the effect on impact behaviour of factors such as magnitude of preload, impact velocity and specimen geometry.

\section{Finite element modelling methodology}

The model was developed by first calibrating material properties against tension and compression coupon tests. To ensure that the model was accurately simulating impact behaviour, prior to the addition of the preload, a number of simulations were run without an applied preload. Finally impact under tensile preload tests were carried out and various investigations conducted.

The FE software Pam-Crash was chosen since it is an explicit FE code which is highly suited to modelling dynamic, non-linear, short duration events such as the impacts that are the subject of this investigation.

The panels were modelled using two dimensional shell elements since the panels were much longer and wider than they were thick. The impactor was modelled as a rigid wall. The material used in the experimental tests was 
Ciba-Geigy GU230-E01 Uniweave Injectex. This fabric consists of 90\% of fibres in the warp direction, and $10 \%$ in the weft. To model this, a bi-phase fabric material model was chosen.

\subsection{Bi-phase model}

The main reason behind the use of the bi-phase model is that damage in the fibres and matrix can propagate independently, therefore it allows the user to analyse these phases separately [3]. The model defines two separate phases: a unidirectional phase and an orthotropic matrix phase [3]. The matrix phase of the bi-phase model can be further broken down into shear matrix damage and volumetric matrix damage. Shear damage of the matrix occurs as a result of pure shear in the matrix, while volumetric damage occurs as a result of the uniform expansion and contraction of the matrix.

In the bi-phase model, the stiffness and strength of an element are calculated by superimposing the effects of each of the phases. The loss in stiffness of each phase is determined by a damage function, which is based upon allowable strains and damage parameters [3].

Figure 1 shows the relationship between the damage function, the stressstrain curve and the stiffness for each phase. The damage function consists of four stages. Initially the damage is zero, until a threshold strain $\left(\epsilon_{i}\right)$ is reached, during this stage the stiffness remains constant and there is a linear relationship between stress and strain. Through the next two stages (between $\epsilon_{i}<\epsilon<\epsilon_{1}$ and $\epsilon_{1}<\epsilon<\epsilon_{u}$ ) the damage increases and stiffness decreases linearly with increasing strain. The final stage occurs after the ultimate strain $\left(\epsilon_{u}\right)$ is reached. During this stage the damage function asymptotes from its ultimate value $\left(d_{u}\right)$ to 1 and the stress remains at a constant residual value.

The very low stiffnesses and large distortions of highly strained elements lead to numerical instabilities in the finite element solution. The element 
elimination feature of Pam-Crash was used to remove such elements from the models.

\section{Results - tension and compression tests}

Simple tension and compression test models, for which experimental data was available, were used to calibrate the bi-phase failure model. As Figure 2 shows the FE tension and compression test simulations failed within $1 \%$ of the experimental failure results. No data was available to calibrate the bi-phase properties against failure strains.

\section{Results - impact without preload models}

The impact without preload model displayed similar trends and behaviour in terms of damage shape and type as that observed experimentally. However, the damage size predicted in these tests was larger than measured from experimental tests, although it did increase with increasing impact velocity as was expected from experimental results (Figure 3).

Residual tensile strength models displayed similar patterns to those found by other authors, but no experimental data was available for comparison [4]. The residual compressive strength estimated by the finite element analysis was compared to experimental data reported by Herszberg et al. [9]. The results agree well when plotted against the total damage area as shown in Figure 4. However, when plotted against impact energy, the finite element analysis underestimates the residual compressive strength. This is consistent with the overestimation of damage by the FE analysis described above (Figure 3). 
(a) fracturing damage function :

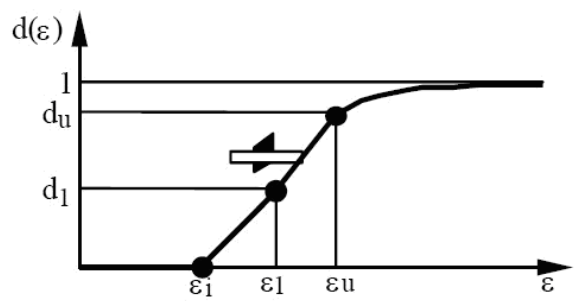

(b) modulus damage:

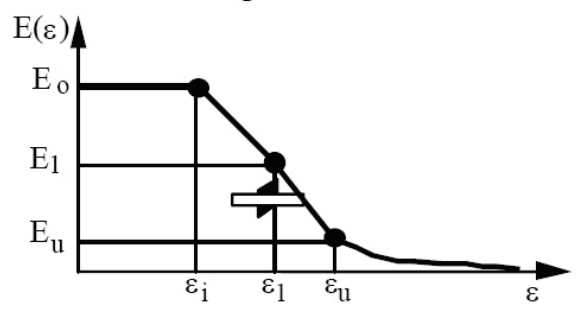

(c) stress-strain diagram:

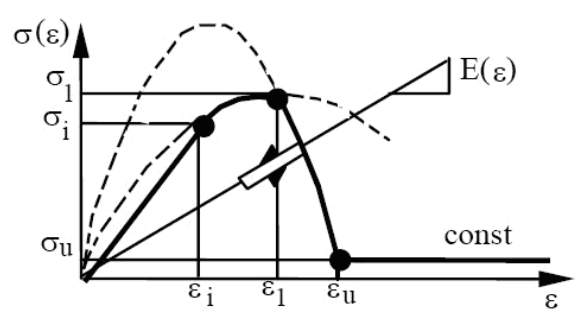

\begin{tabular}{|c|c|}
\hline damage function $\mathrm{d}(\varepsilon)$ & range \\
\hline$\frac{\varepsilon-\varepsilon_{\mathrm{i}}}{\varepsilon_{1}-\varepsilon_{\mathrm{i}}} \mathrm{d}_{\mathrm{l}}$ & $\varepsilon_{\mathrm{i}}<\varepsilon<\varepsilon_{1}$ \\
\hline$\frac{\varepsilon-\varepsilon_{1}}{\varepsilon_{\mathrm{u}}-\varepsilon_{1}}\left(\mathrm{~d}_{\mathrm{u}}-\mathrm{d}_{1}\right)+\mathrm{d}_{\mathrm{l}}$ & $\varepsilon_{1}<\varepsilon<\varepsilon_{\mathrm{u}}$ \\
\hline $1-\left(1-\mathrm{d}_{\mathrm{u}}\right) \varepsilon_{\mathrm{u}} / \varepsilon$ & $\varepsilon_{\mathrm{u}}<\varepsilon<\infty$ \\
\hline
\end{tabular}

$\varepsilon=$ equivalent strain $\quad \mathrm{E}_{0}=$ initial elastic modulus

$\varepsilon_{\mathrm{i}}=$ initial threshold strain $\sigma_{\mathrm{u}}=$ residual constant stress level

$\varepsilon_{1}=$ intermediate $\quad \varepsilon_{\mathrm{u}}=$ ultimate strain

$\mathrm{d}_{\mathrm{l}}=$ intermediate damage $\quad \mathrm{d}_{\mathrm{l}}=$ ultimate damage

\begin{tabular}{|l|}
\hline modulus damage \\
\hline $\mathrm{E}(\varepsilon)=(1-\mathrm{d}(\varepsilon)) \mathrm{E}_{0}$ \\
\hline
\end{tabular}

Figure 1: Bi-phase damage, modulus and stress-strain diagrams [3]. 


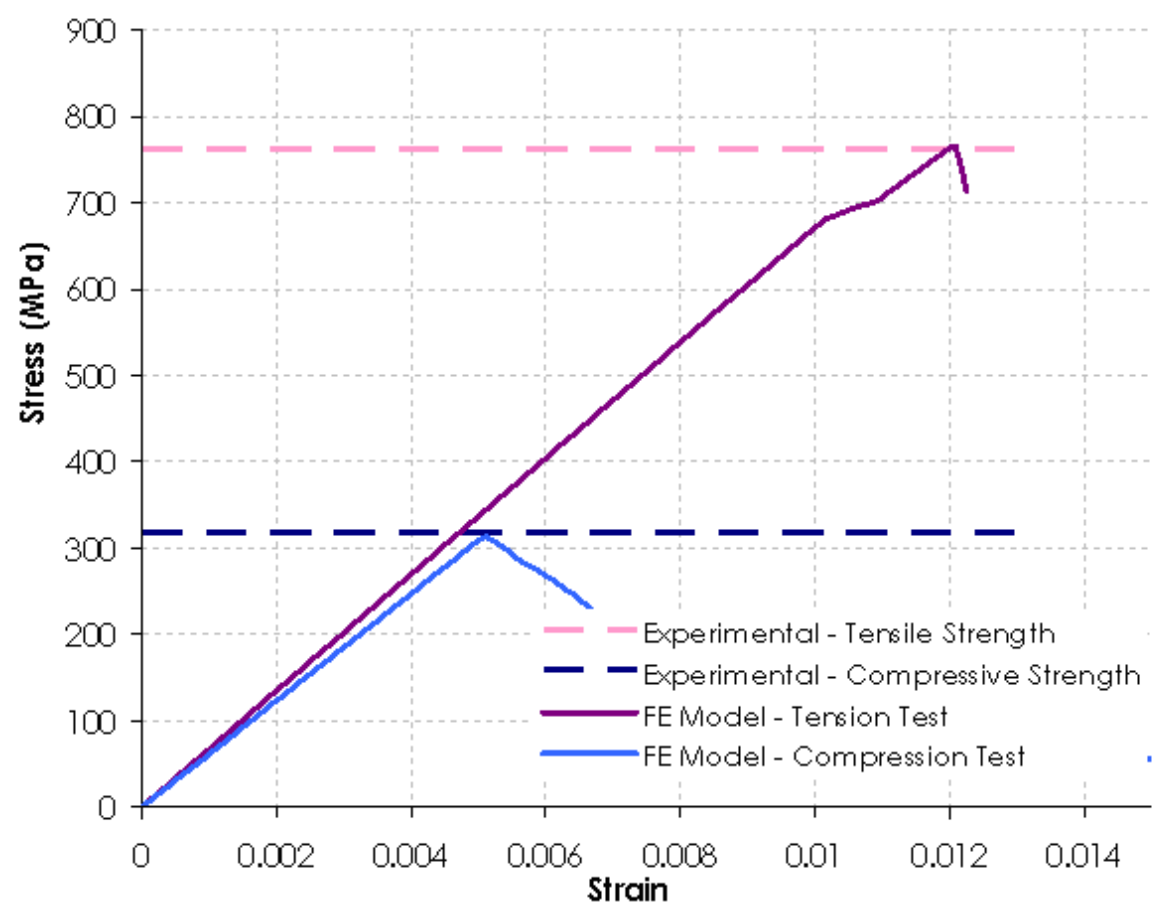

FiguRE 2: finite element tension and compression simulations versus experimental results. 


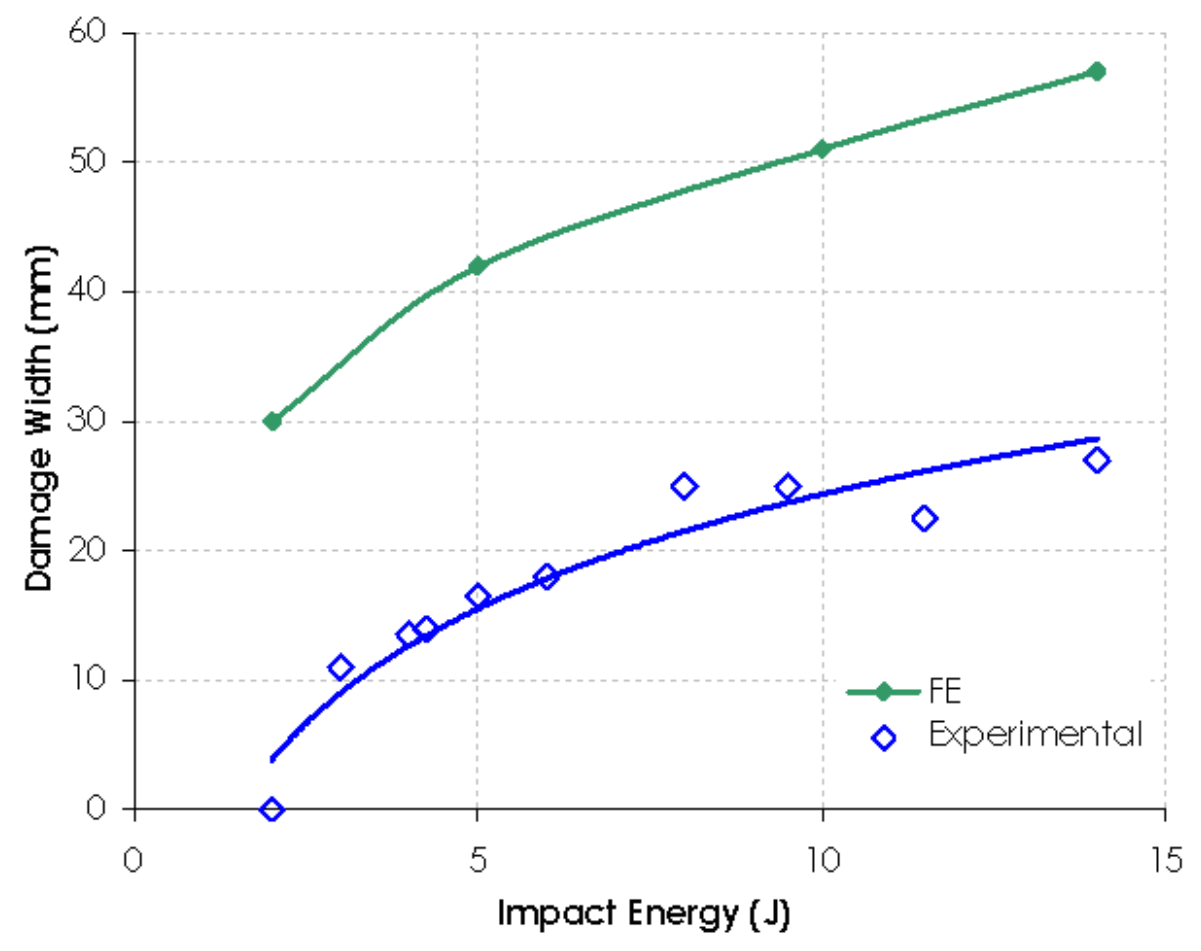

FiguRE 3: Damage width against impact energy. 


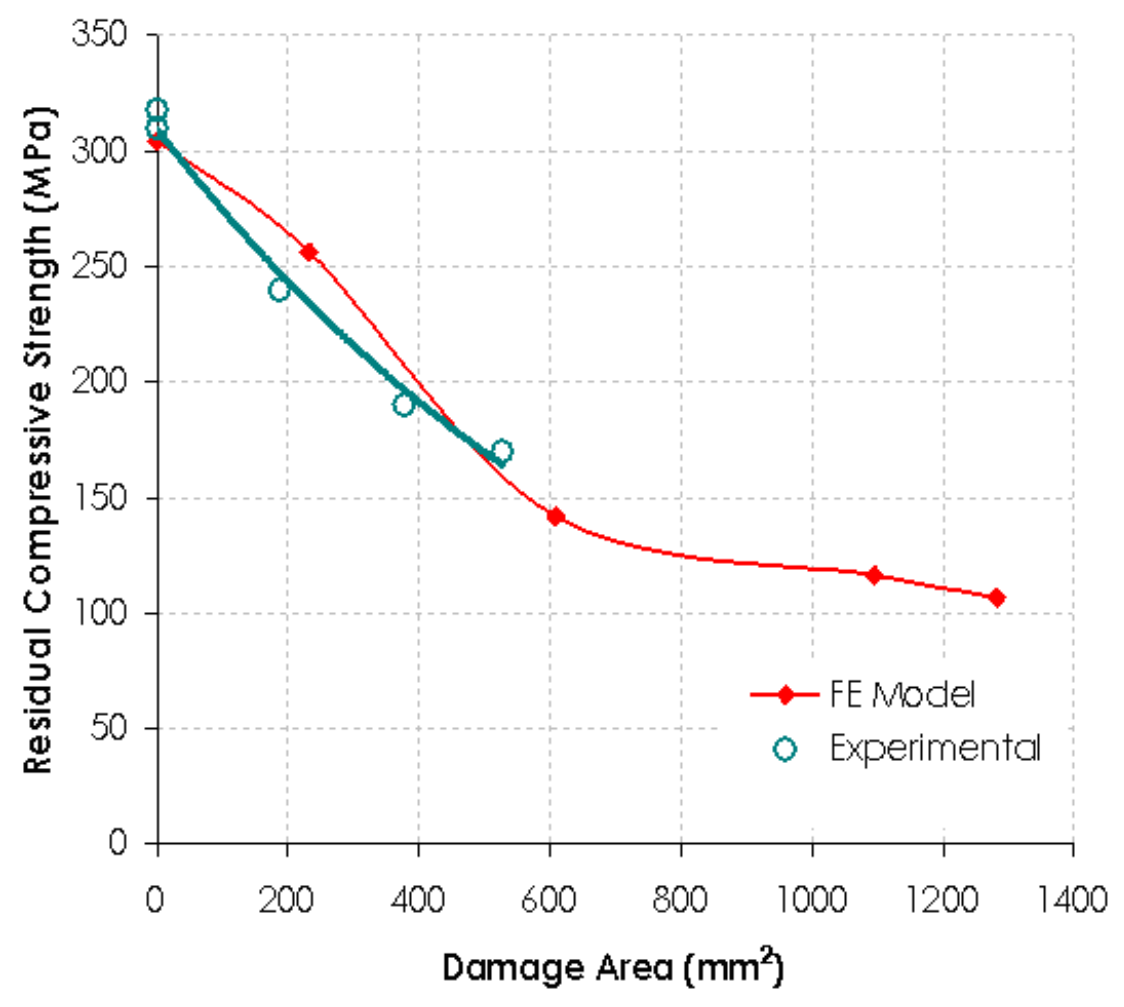

FiguRE 4: Residual compressive strength versus damage area. 

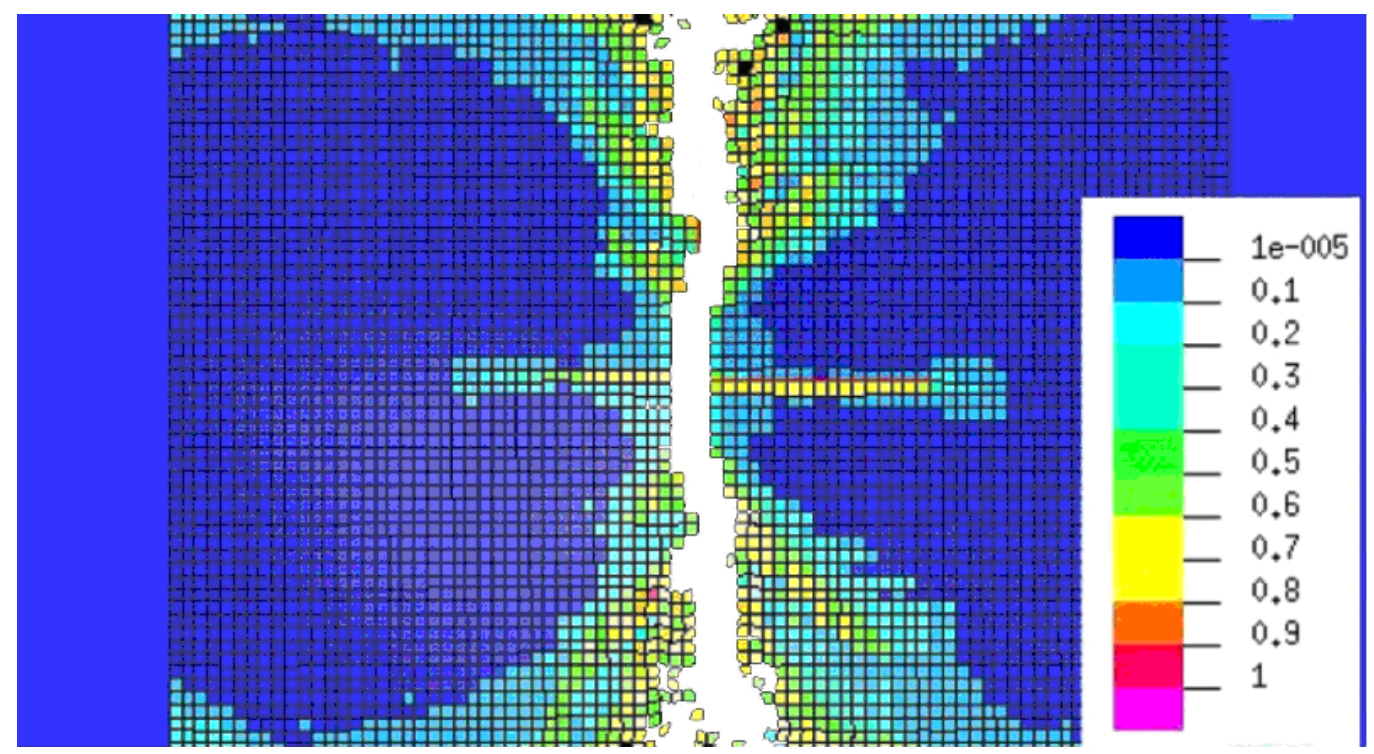

FiguRE 5: Total damage plot of catastrophic failure, $88 \mathrm{kN}$ preload.

\section{Results - impact under preload models}

\subsection{Damage analysis}

Above certain velocity preload combinations the panels were found to fail catastrophically upon impact (Figure 5). When impacts were plotted against impact velocity and preload a boundary formed between panels that were damaged, but sustained the applied preload and those which failed catastrophically or were penetrated (Figure 7). Generally catastrophic failure occurred at higher preloads $(70-100 \mathrm{kN})$, while for lower preloads, once the critical velocity was reached the impactor penetrated the panel completely as shown in Figure 6. 


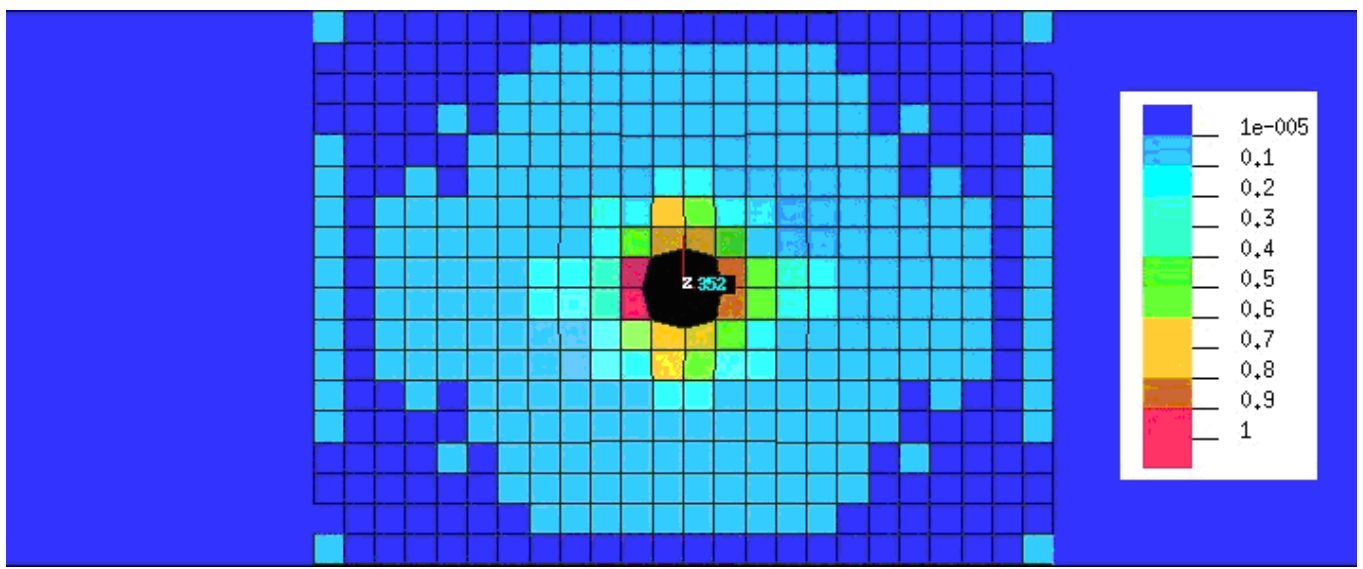

FIgURE 6: Total damage plot of penetration, $49 \mathrm{kN}$ preload.

\subsection{Mesh size sensitivity}

The mesh size was found to have significant effect on the results of the critical velocity boundary. As Figure 7 shows, an increasing mesh size increased the steepness of the critical velocity boundary. However, the FE results were lower than the experimental results for all cases except the $10 \times 10 \mathrm{~mm}$ mesh.

\subsection{Panel size}

Panel size was investigated to determine whether increasing the panel size would have an effect on the critical velocity for a particular preload. This was done by doubling the panel size, while keeping the mesh size the same. It was found that twice the load was needed to cause catastrophic failure at the same impact velocity. However, if the critical velocity boundary was plotted on axis of prestress and impact velocity, then the critical velocity boundary for both panels was exactly the same. 


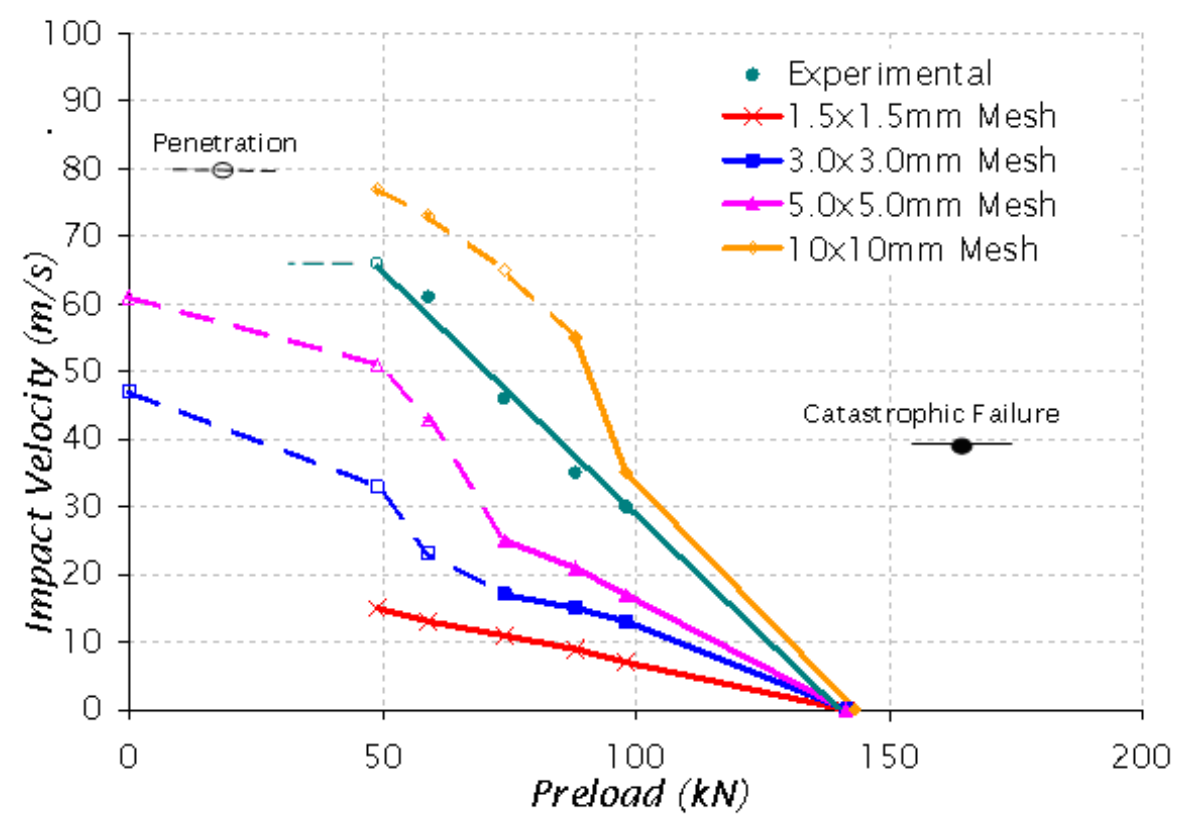

FiguRE 7: Effect of mesh size on the critical velocity boundary. 


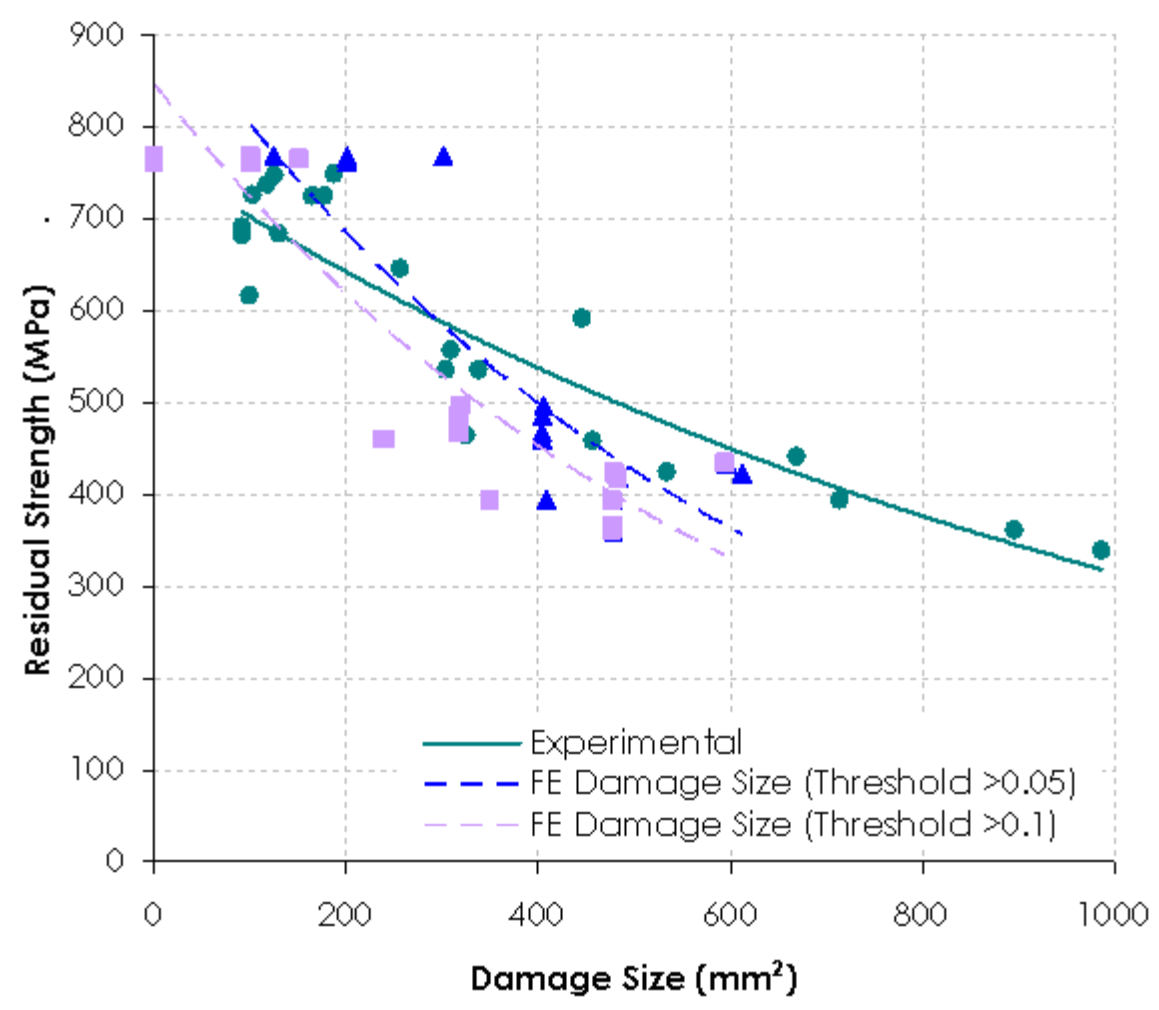

Figure 8: Residual strength versus damage size.

\subsection{Residual tensile strength}

As in the impact without preload model, residual strength results were found to be very close to experimental results when plotted against damage size, this is shown in Figure 8. However, residual strength was under-predicted when plotted against impact velocity. 


\section{Discussion of modelling limitations}

The results suggest that the model is accurately predicting in-plane tests under static loading conditions, as is evidenced by the result of residual strength versus damage size plots, ultimate strength tests and calibration tests. However, there are issues with predicting damage and failure caused by dynamic transverse loading cases. The FE results are very conservative compared with experimental results and greatly over predict damage size and under predict the critical velocity for catastrophic failure. Despite this over prediction, in most cases the trends observed from FE simulations are consistent with those observed in experimental tests. Although, there are some discrepancies between the type (matrix cracking, delamination, indentation, fibre rupture) and shape of damage observed in FE simulations as compared to experimental tests. Discussed below are a number of factors that may be contributing to the differences observed between the experimental and $\mathrm{FE}$ results.

The bi-phase material properties were calibrated to in-plane tensile and compressive coupon tests. Since properties such as stiffness and strength may be different in bending than for in-plane loading, this may account for the accuracy of residual and ultimate strength tests, but the poor correlation between experimental and $\mathrm{FE}$ results for impact tests which cause out of plane deformations. It would be expected that the properties of the material may be higher in flexure than in-plane and therefore, if these could be used in the calibration process, then the damage size might be reduced and the preload-velocity combination which causes catastrophic failure increased.

The strain rate sensitivity of the material may also have an effect on results. The experimental tension and compression tests used to calibrate the model were carried out at a low strain rate. However, impact events cause a dynamic load to be applied at a high strain rate to the material. Since the material may be strain rate sensitive, that is, its properties such as stiffness and strength may increase with increasing strain rate; a model calibrated at low strain rates may not accurately represent the material behaviour when 
subjected to loading at high strain rates.

A lack of experimental data available meant that a number of assumptions were made in determining and calibrating the bi-phase properties. As such, it is possible that some of these inputs were not realistic and may have had an effect on the outcomes of the model. Another limitation of the bi-phase model used to conduct the simulations is that while it is able to split damage into separate fibre and matrix phases, the type of damage depicted is not necessarily easily comparable with experimental results.

Damage such as fibre or tow splitting is not shown in bi-phase model as fibre damage, since the model considers the fibres to be unidirectional and therefore can only model fibre rupture. However, it may be depicted as matrix damage. An overall $\mathrm{FE}$ damage plot that considers fibre rupture and matrix cracking is not comparable with a C-scan image of an experimental test specimen which would predominantly show only delaminations. These problems make a direct comparison of experimental and predicted damage difficult.

Delamination damage between the plies of the laminate is not accounted for in the bi-phase model. Since delamination failure absorbs a large amount of energy during impact, the lack of this type of failure mechanism in the model may have a significant effect on the results. The FE model may absorb this energy through a different failure mechanism which does not occur in physical tests, or the damage caused in other failure modes may simply increase to absorb the energy. This may account for the general over prediction of damage size as depicted by the model compared with experimental results.

\section{Conclusion}

Modelling of impacts on unloaded panels correlated well with experimental results in terms of damage type and residual strength. However, the damage 
size was over predicted in most cases.

Modelling of impacts under tensile preload displayed similar behaviours and trends to those observed experimentally. However, damage size was over estimated and the catastrophic failure boundary was predicted at lower preload-velocity combinations than found in experimental tests. Some variance in the damage type, shape and location was also observed when compared with experimental results. Discrepancies were a result of the modelling techniques used, limitations of the model in depicting various forms of damage and the method of calibrating material properties.

The model predicted that above a critical velocity catastrophic failure of the panel will occur for high preloads, while at lower preloads the impactor penetrates the panel. It was found that the critical velocity decreased with increasing preload. It was also found that as the velocity increased the damage size increased and residual strength decreased. The damage size and residual strength were found to be independent of the preload, except in regions close to the critical velocity.

\section{References}

[1] S. Abrate. Impact on Laminated Composite Materials, Appl Mech Rev, 44, 1991, 155-190. C70

[2] W. J. Cantwell and J. Morton. The Impact Resistance of composite Materials, A Review, Composites, 22, 1991, 347-360. C70

[3] ESI Group. PAM-CRASH 2004, PAM-SAFE 2004: Solver Notes Manual, ESI Group, France, 2004. C72, C74

[4] I. Herszberg, T. Weller, K. H. Leong and M. K. Bannister. The Residual Tensile Strength of Stitched and Unstitched Carbon/Epoxy Laminates, in Proceedings of the First Australasian Congress on 
Applied Mechanics, Melbourne, Australia, Feb 21-23, 1996. C70, C71, $\mathrm{C} 73$

[5] A. Kelkar, J. Sankar and C. Grace. Behavior of Tensile Preloaded Composites Subjected to Low-velocity Impact Loads, Recent Advances in Solids/Structures and Application of Metallic Materials ASME, 369, 1997, 39-46. C71

[6] A. T. Nettles and D. G. Lance. The Effects of Compressive Preloads on the Compression-After-Impact Strength of Carbon Epoxy, NASA Technical Paper 3303, 1992. C71

[7] M. D. Robb, W. S. Arnold and I. H. Marshall. The damage tolerance of FRP laminates under biaxial prestress, Composite Structures, 32, 1995, 141-149. C70

[8] Z. Zhang, G. A. O. Davies, and D. Hitchings. Impact damage with compressive preload and post-impact compression of carbon composite plates, International Journal of Engineering, 22, 1999, 485-509. C70

[9] I. Herszberg, K. H. Leong and M. K. Bannister. The Effect of Stitching on the Impact Damage Resistance and Tolerance of Uniweave Carbon/Epoxy Laminates, in Proceedings of the Fourth International Conference on Automotive Composites, Nottingham, UK, Sep 6-7, 1995. C73 